\title{
Correction to: Orally delivered water soluble coenzyme Q10 (Ubisol-Q10) blocks on-going neurodegeneration in rats exposed to paraquat: potential for therapeutic application in Parkinson's disease
}

Krithika Muthukumaran ${ }^{1,2}$, Samantha Leahy ${ }^{1,2}$, Kate Harrison ${ }^{1,2}$, Marianna Sikorska $^{3}$, Jagdeep K. Sandhu ${ }^{3}$, Jerome Cohen ${ }^{1,2}$, Corrine Keshan 1,2, Daniel Lopatin ${ }^{1,2}$, Harvey Miller ${ }^{3}$, Henryk Borowy-Borowski ${ }^{3}$, Patricia Lanthier ${ }^{3}$, Shelly Weinstock ${ }^{4}$ and Siyaram Pandey ${ }^{1,2^{*}}$

\section{Correction to: BMC Neuroscience (2014) 15:21} https://doi.org/10.1186/1471-2202-15-21

Following publication of the original article [1], it was reported that there was an error in Figs. $2 \mathrm{~B}$ and $3 \mathrm{~B}$. One of the figure panel (PQ2 High Magnification) from
Fig. 2B was mistakenly duplicated in Fig. 3B (PQ2 High Magnification) Also a high magnification panel of Fig. $2 \mathrm{~B}$ (control) was put in in Fig. 3B (PQ + Ubisol $\mathrm{Q}_{10} 4$ weeks). We have corrected this error.

The corrected versions of Figs. 2B and 3B are included in this erratum. 
Figure 2B:
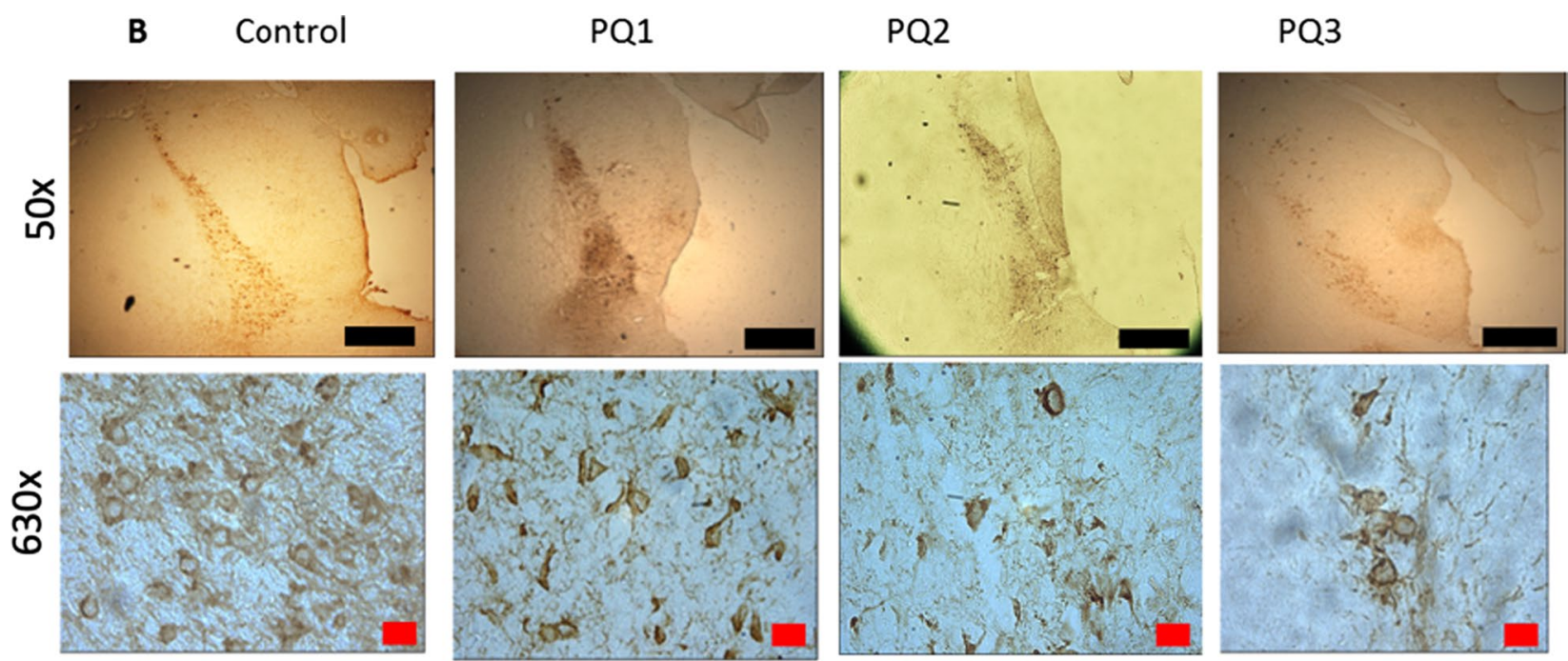

\section{Scale bar for $50 x=200$ microns}

Scale bar for $630 \mathrm{x}=20 \mathrm{microns}$

Figure 3B:
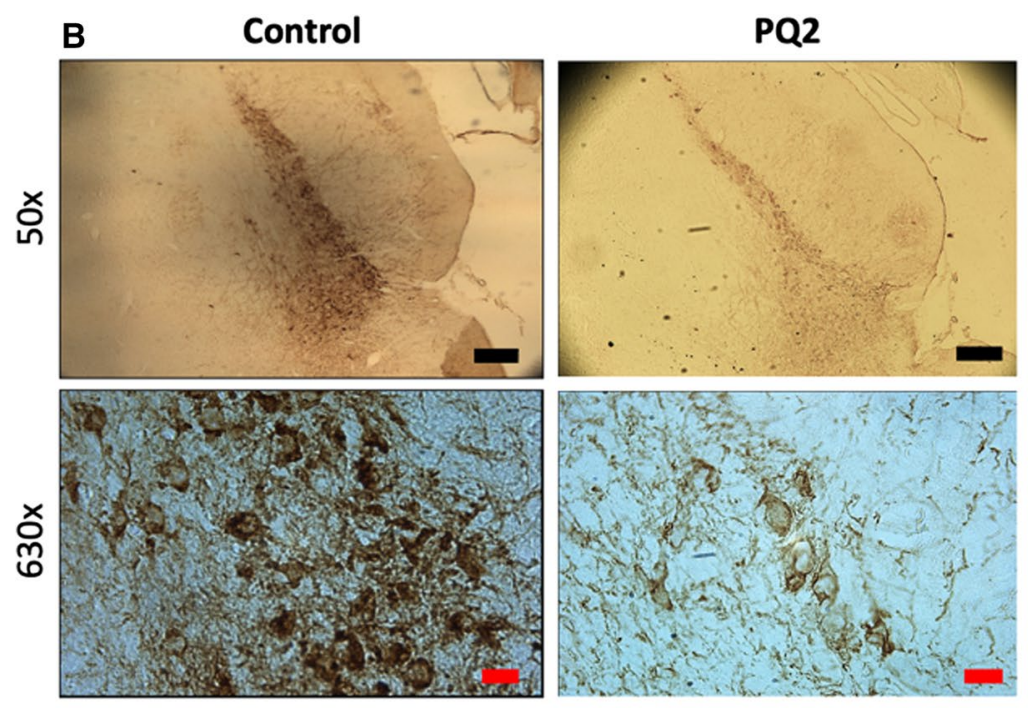

PQ2 + Ubisol- $Q_{10} 4$ Weeks

Scale bar for $50 x=200$ microns

Scale bar for $630 \mathrm{x}=20 \mathrm{microns}$ 


\section{Author details}

${ }^{1}$ Chemistry and Biochemistry, University of Windsor, 401 Sunset Ave, Windsor, ON, Canada. ${ }^{2}$ Psychology, University of Windsor, Windsor, ON, Canada. ${ }^{3}$ Translational Bioscience, Human Health Therapeutics Portfolio, National Research Council Canada, Ottawa, ON K1A OR6, Canada. ${ }^{4}$ Zymes LLC, Hasbrouck Heights, NJ, USA.

Published online: 20 December 2021

\section{Reference}

1. Muthukumaran K, Leahy S, Harrison K, Sikorska M, Sandhu JK, Cohen J, Keshan C, Lopatin D, Miller H, Borowy-Borowski H, Lanthier P, Weinstock S, Pandey S. Orally delivered water soluble coenzyme $\mathrm{Q}_{10}\left(\right.$ Ubisol- $\left.\mathrm{Q}_{10}\right)$ blocks on-going neurodegeneration in rats exposed to paraquat:

potential for therapeutic application in Parkinson's disease. BMC Neurosci. 2014;15:21. https://doi.org/10.1186/1471-2202-15-21.

\section{Publisher's Note}

Springer Nature remains neutral with regard to jurisdictional claims in published maps and institutional affiliations. 